\title{
Using Systems Thinking and System Dynamics Modeling to Understand Rebound Effects ${ }^{1}$
}

\author{
Mohammad Ahmadi Achachlouei ${ }^{2,3,4}$ and Lorenz M. Hilty ${ }^{2,3,5}$
}

\begin{abstract}
Processes leading to an increase of demand for a resource as a consequence of increasing the efficiency of using this resource in production or consumption are known as (direct) rebound effects. Rebound effects at micro and macro levels tend to offset the reduction in resource consumption enabled by progress in efficiency. Systems thinking and modeling instruments such as causal loop diagrams and System Dynamics can be used to conceptualize the structure of this complex phenomenon and also to communicate model-based insights. In passenger transport, the rebound effect can be invoked by increased cost efficiency (direct economic rebound) and/or increase in speed (time rebound). In this paper we review and compare two existing models on passenger transportincluding a model on the role of information and communication technologywith regard to the feedback loops used to conceptualize rebound effects.
\end{abstract}

Keywords Rebound effect, energy efficiency, systems thinking, systems modeling, system dynamics, causal loop diagrams, passenger transport, ICT, time rebound, direct rebound

\section{Introduction}

Energy efficiency is one of the main policy options to fight global climate change (e.g. see [1]). Energy efficiency helps devices and infrastructures provide the same services using less energy, and thus can be a solution for reducing greenhouse gas (GHG) emissions. However, it can also induce additional demand if the energy

\footnotetext{
${ }^{1}$ This is the extended version of the paper "Modeling Rebound Effects in System Dynamics" by M. Ahmadi Achachlouei and L.M. Hilty, published in the proceedings of EnviroInfo 2014: http://oops.uni-oldenburg.de/1919/

${ }^{2}$ KTH Royal Institute of Technology, SE-100 44 Stockholm, Sweden, Division of Environmental Strategies Research (fms). Email: Mohammad.Achachlouei@abe.kth.se

${ }^{3}$ KTH Royal Institute of Technology, SE-100 44 Stockholm, Sweden, Centre for Sustainable Communications (CESC)

${ }^{4}$ Empa - Swiss Federal Laboratories for Materials Science and Technology, Technology and Society Lab , 9014 St. Gallen, Switzerland

${ }^{5}$ University of Zürich, , Department of Informatics, CH-8050 Zürich, Switzerland
}

\footnotetext{
Accepted Author Manuscript of the following publication:

Ahmadi Achachlouei, M., Hilty, L.M. (2016): Using Systems Thinking and System Dynamics Modeling to Understand Rebound Effects. In: Marx Gomez, J., Sonnenschein, M., Vogel, U., Winter, A., Rapp, B., Giesen, N. (eds): Advances and New Trends in Environmental and Energy Informatics, Springer International Publishing Switzerland, pp. 237-255
} 
saved leads to a lower price of the final service. This induction is known as the rebound effects (or take-back effects) [2]. At a micro level, the rebound effect may occur through (i) creating more demand for the cheaper service (direct rebound effects), and/or (ii) increasing income available for general consumption (indirect rebound effects) [3]. At a macro level, increased efficiency in the production and use of energy will yield a series of supply and demand adjustments occurring over time [3] "with energy-intensive goods and sectors likely to gain at the expense of less energy-intensive ones" [4] (economy-wide effects).

Various methods have been employed to understand and explain the rebound effects. Economic studies have sought to estimate the magnitude of these rebound effects [4], [5]. Quasi-experimental approaches have been used to measure the demand for the service before and after an efficiency improvement [6]. Moreover, sociological and psychological studies have addressed the ways in which efficient solutions are being used in people's everyday life (e.g. see [7], [8]).

To better understand the complexity of rebound effects of investments in efficiency improvements, system-theoretical approaches and dynamic models have to be used. Systems thinking and modeling instruments, such as causal loop diagrams and System Dynamics simulation, by highlighting the causal structure of the system and feedback effects, provide effective approaches to conceptualizing such complex phenomena and communicating model-based insights [9]-[11].

A number of studies have employed systems thinking and modeling instruments to address rebound effects. Hilty et al. [12] used such tools (at a quantitative level) to include time rebound and direct economic rebound in their study of effects of information and communication technology (ICT) on environmental sustainability. Stepp et al. [13] employed causal loop diagrams to highlight the potential unintended consequences and rebound effects when studying the role of feedback effects in GHG mitigation policies in the transport sector. Peeters [14] used causal loop diagrams to investigate the positive and negative role (and rebound effects) of technological progress in the context of GHG emissions from tourism transport. In a recent study, Dace et al. [15] built causal loop diagrams and a System Dynamics simulation model to analyze effects of eco-design policy on packaging waste management systems, showing how tax can help counteract a rebound effect originated from eco-design.

In passenger transport, the direct rebound can be induced through increases in fuel efficiency or other improvements reducing the variable cost per person-kilometer (direct economic rebound) and/or increase in speed of transport modes (time rebound). In this paper, using the domain of passenger transport as an example, we review and compare two existing models on passenger transport (developed in the context of environmental impacts of transport), including a model on the effects of ICT on transport. We investigate two research questions:

(i) What are the main feedback loops used in modeling rebound effects (with a focus on direct economic rebound and time rebound)? 
(ii) What is the contribution of systems thinking and the System Dynamics approach to the analysis of rebound effects?

The current paper is organized as follows. First, brief definitions of the concepts of rebound effects, elasticity of demand, System Dynamics, and causal loop diagrams are presented. Section 3 introduces the two models discussed in this paper. Section 4 and 5 provide a detailed discussion of the feedback loops in Model 1 and Model 2 used to model rebound effects. Section 5 discusses the main findings and the contribution of systems thinking and modeling to the rebound literature. Section 7 concludes the paper.

\section{Main concepts}

\subsection{Rebound effects}

Rebound effect is an "umbrella term for a variety of economic responses to improved energy efficiency and 'energy-saving' behavioral change" [16]. Rebound effects can be categorized as follows [17], [18] (See [19] for a brief history of rebound analysis):

- Direct economic rebound effects: When cheaper energy (or energy efficiency improvement in using energy-intensive goods) induces price reductions that trigger an increase in the demand for the cheaper good. (The good can be a tangible good or an intangible service.)

- Time rebound effects (a kind of direct rebound), which is based on time efficiency in consumption: If people can consume a product or service in less time, they tend to demand more of it.

- Indirect rebound effects (income rebound): If the consumer saves money on one good (because it is used more efficiently and its price goes down) her disposable income is higher than the income she can spend-because she didn't use the money for the purpose, she can use it for something else that also requires energy for its provision.

- Economy-wide rebound effects, which appear when declining energy prices induce a reduction in the prices of intermediate and final goods throughout the economy, and cause structural changes in production patterns and consumption habits.

In this paper we only address the direct economic rebound and time rebound in the field of passenger transport. If the efficiency increase is enabled by ICT, both direct and indirect rebound effects are subsumed under the so-called third-order effects of ICT [20].

Rigorous definitions of rebound effects have been provided by Khazzum [21], Berkhout et al [2] and Sorrell and Dimitropoulos [4]. The magnitude of the direct economic rebound effect depends on demand elasticity. The efficiency elasticity of useful work can be taken as a measure of the direct rebound effect [4]:

\footnotetext{
Accepted Author Manuscript of the following publication:

Ahmadi Achachlouei, M., Hilty, L.M. (2016): Using Systems Thinking and System Dynamics Modeling to Understand Rebound Effects. In: Marx Gomez, J., Sonnenschein, M., Vogel, U., Winter, A., Rapp, B., Giesen, N. (eds): Advances and New Trends in Environmental and Energy Informatics, Springer International Publishing Switzerland, pp. 237-255
} 


$$
\eta_{s}(S)=\frac{\partial S}{\partial \varepsilon} \frac{\varepsilon}{S}
$$

where $S$ represents the useful work (which can be measured by a variety of thermodynamic or physical indicators [4]; e.g. passenger-kilometers in the case of transport), and $\varepsilon$ represents the energy efficiency of an energy-transforming system (which can be defined as $\varepsilon=S / E$, where $E$ represents the energy input required for a unit output of useful work).

Economic elasticity of demand with regard to price, or price elasticity of demand (PED) is defined as the percentage change in demand divided by the percentage change in price (See [22] for an overview of price elasticities of transport demand). Use efficiency can be expressed via price as an input for calculating price elasticity of demand. If for example a vehicle is used more efficiently by transporting more persons at a time, the cost per passenger kilometer is lower, which can lead to an increase in demand. Given the elasticity of demand $(\eta)$ for energy services (such as transport) with regard to energy cost of the energy service $\left(\mathrm{P}_{\mathrm{S}}\right)$ or with regard to price of energy $\left(\mathrm{P}_{\mathrm{E}}\right)$, we can extend the definition of direct rebound effect (equation (1)) as follows (see [4] for details):

$$
\eta_{s}(S)=-\eta_{P_{s}}(S)
$$

and

$$
\eta_{s}(S)=-\eta_{P E}(S)
$$

Moreover, we can consider the effect of more demand originated from improved time efficiency $(\theta)$, "the influence of time costs on the rebound effect and the existence of a parallel rebound effect with respect to time" [4]. For example, one may choose faster transport modes that are more energy-intensive and more polluting; or one may travel longer or more frequently because of better time utilization using mobile ICT. The time rebound effect can be defined using an extended version of equation (1) (see [4] for details):

$$
\eta_{s}(S)=-\eta_{P S}(S)+\left[\eta_{P T}(S) \eta_{\theta}\left(P_{T}\right) \eta_{s}(\theta)\right]
$$

where the additional term in square brackets (compared to equation (2)) is the product of the elasticity of demand for useful work (e.g. transport) with respect to time costs $\left(\eta_{\mathrm{PT}}(\mathrm{S})\right)$, the elasticity of time costs with respect to time efficiency $\left(\eta_{\theta}\left(\mathrm{P}_{\mathrm{T}}\right)\right)$ and the elasticity of time efficiency with respect to energy efficiency $\left(\eta_{e}(\theta)\right)[4]$

Data availability of any elasticity values mentioned in equations (1) to (4) - see more definitions in [4] — can guide us to choose the most appropriate equation for the magnitude of direct rebound effect in a given analysis task.

\subsection{Systems Thinking and Modeling}

Systems thinking and modeling, as a non-linear way of thinking about the sources of and the solutions to modern problems [23], "offers a holistic way of 
appreciating all dimensions of a complex problem" [24]. This approach has been applied to "almost any problem area because of its generality" [25] such as strategy and organizations, production and operations, ecology and agriculture, medicine and health, and sustainable development. In their review of theoretical aspects and applications of systems thinking and modeling (or "the systems approach"), Mingers and White [25] conclude that that while this approach "may not be well established institutionally, in terms of academic departments, it is incredibly healthy in terms of the quantity and variety of its applications" [25].

In this paper, we focus on two systems approaches: Causal loop diagrams (CLDs) and System Dynamics simulation modeling (Sometimes the CLD is referred to as "qualitative System Dynamics" [26]). Although it is common to first build a CLD and then a System Dynamics simulation model, it is also possible to use only CLDs without formal computer simulation modeling "to assist issue structuring and problem-solving" [26] and when "the aim of the project is simply greater understanding of the situation, or where reliable quantitative information is not available" [25]. CLDs can provide insight into policy issues by inferring, rather than calculating [26].

The main concept in CLDs and System Dynamics is the representation of system behavior over time via feedback loop structures and cause-and-effect analysis and, used for theory building, policy analysis and strategic decision support [9]-[11]. A feedback approach "supports closing open sequences of causes and expected effects, thus overcoming barriers in traditional linear thinking, namely the tendency to neglect unintended consequences, which often stand at the root of policy implementation failure" [27].

A feedback loop is a closed path of causal influences and information, forming a circular-causal loop of information and action. If the tendency in the loop is to reinforce the initial action, the loop is called a positive or reinforcing feedback loop; if the tendency is to oppose the initial action, the loop is called a negative, counteracting, or balancing feedback loop [11].

In a CLD, relationships between variables are depicted using arrows with a positive $(+)$ or negative (-) sign placed besides the arrowhead to indicate link polarity (e.g. see Fig. 1 and Fig. 2 in the next sections). A positive link polarity implies that "if a cause increases, the effect increases above what it would otherwise have been" and vice versa [10]. Similarly, a negative link polarity "means that if the cause increases, the effect decreases below what it would otherwise have been" and vice versa [10]. A CLD (as a qualitative technique) can be translated into stocks (accumulations or levels) in the system and their inflows and outflows (rates) [10, Ch. 6]. Mathematically, a system of difference equations is used to define computational System Dynamics models [10], [11].

\footnotetext{
Accepted Author Manuscript of the following publication:

Ahmadi Achachlouei, M., Hilty, L.M. (2016): Using Systems Thinking and System Dynamics Modeling to Understand Rebound Effects. In: Marx Gomez, J., Sonnenschein, M., Vogel, U., Winter, A., Rapp, B., Giesen, N. (eds): Advances and New Trends in Environmental and Energy Informatics, Springer International Publishing Switzerland, pp. 237-255
} 


\section{Selected models}

Two models from literature have been chosen to illustrate how rebound effects are modeled using System Dynamics feedback loops. The first example (Model 1) models the dynamics of how ICT positively or negatively affects the passenger transport demand and modal split. The second example (Model 2) models the dynamics of how pollution-saving technologies positively or negatively affect the tourist transport demand and GHG emissions.

Feedback loops related to Model 1 and Model 2 (as shown in Fig. 1 and Fig. 2, respectively), which are used to conceptualize the rebound effects, are presented and discussed in the following sections.

\section{Model 1: Future Impacts of ICT on Environmental Sustainability-Submodel Passenger Transport (IPTS Study)}

In 2002, the European Commission's Institute for Prospective Technological Studies (IPTS) commissioned a study to explore the current and future environmental effects of ICT to a consortium led by the Institute for Futures Studies and Technology Assessment (IZT), Berlin, Germany. The aim of the study was to estimate positive and negative effects of the ICT on environmental indicators with a time horizon of 20 years. The method applied was to develop future scenarios, build a model based on the System Dynamics approach, validate the model and use it to run quantitative simulations of the scenarios. The results were published in 2003 and 2004 in five interim reports [28]-[32] (the 4th interim report [31] describes the model and data used), one final report [33] and several articles [12], [20], [34]. The results of this study, which we will call "the IPTS study" for short in this article, were recently revisited and revalidated in [35].

In the passenger transport submodel of the IPTS study (called Model 1 here), the goal was to calculate the volume of passenger transport demand (in passengerkilometers, pkm, for different transport modes) changing over time due to the causal mechanisms modeled in terms of stocks and flows. Fig. 1a shows an aggregated conceptual model for the passenger transport submodel in the IPTS study [12], [31]. Fig. 1b presents the three main feedback loops in this model: cost efficiency loop, resource scarcity loop, and mode shift loop. For simplicity, the model has been reduced to two competing modes of transport, here called "A" and "B" (which can be thought of, e.g. private car and public bus), whereas the original model differentiates among five modes of physical transport and is more complex. Each loop exists twice (symmetrically) because of the two modes chosen here for illustration, i.e., mode A and B. 
Fig. $1 \mathrm{~b}$ is not a pure CLD, since it includes parts of the stock-and-flow diagram to better describe the central mechanism of shifting transport demand between traffic modes. In the IPTS study, this mechanism was generalized to $n$ modes based on multimodal passenger transport models developed by Hilty [36], [37]. Five traffic modes were differentiated in Model 1: Private car, bus and coach, tram and metro, train, and air transport. In addition, three modes of "virtual mobility" including home-based telework, virtual meetings, and teleshopping were represented, which was a new feature developed for the IPTS study.

Two types of rebound effect were modeled in Model 1 with regard to passenger transport [12]: direct economic rebound effects and time rebound effects. The following subsections present how these two categories of rebound effects were addressed in Model 1.

\subsection{Direct economic rebound effects in Model 1}

The direct economic rebound effects in Model 1 are represented via demand elasticities for passenger transport. The IPTS study considered the rebound induced by the price level of each passenger transport mode: besides changes of market prices (e.g. the oil price), which are external to the mode, higher efficiency (e.g. fuel efficiency of vehicles) can lead to lower prices per pkm (direct rebound effect), which will create more demand according to empirical elasticity parameters. As shown in Fig. 1b the elasticity parameter of each mode together with per-pkm price of the mode are controlling the inflow rate of transport volume associated with the mode.

Elasticity of demand with regard to price is defined as a relative change in demand divided by a relative change in price. It will not be realized immediately, i.e., when the price changes, in that moment no change occurs in demand, but gradually over the years. Empirical studies of elasticity of demand therefore usually distinguish between "short term" and "long term" elasticity. Model 1 expresses the temporal aspect of elasticity by adding a time constant to each elasticity value. Adaptations in Model 1 including the elasticity-based adaptation of demand (also the shift between modes based on relative speed and time deficit, which will be discussed later) are not immediate in Model 1, but controlled by time constants.

Direct economic rebound effects in Model 1 are represented via the following feedback loops (see Fig. 1): cost efficiency loop and resource scarcity loop.

\section{a) Cost efficiency loop}

Traffic volume (pkm) for each mode-modeled as a stock-is controlled by an inflow rate depending on the elasticity parameter and the per-pkm fuel price associated with the mode. (For simplicity, fuel is used here a pars pro toto for the sum of all resources needed to produce a pkm which cause variable cost; these resources may vary depending on the mode of transport.)

\footnotetext{
Accepted Author Manuscript of the following publication:

Ahmadi Achachlouei, M., Hilty, L.M. (2016): Using Systems Thinking and System Dynamics Modeling to Understand Rebound Effects. In: Marx Gomez, J., Sonnenschein, M., Vogel, U., Winter, A., Rapp, B., Giesen, N. (eds): Advances and New Trends in Environmental and Energy Informatics, Springer International Publishing Switzerland, pp. 237-255
} 
The elasticity parameter represents "classical" elasticity of demand with regard to price (in Model 1: the "PED" submodel included for each mode). Because the fuel price per pkm does not only depend on the fuel price per liter but also on the efficiency with which the fuel is used ("Efficiency of A with regard to fuel"), the price of $1 \mathrm{pkm}$ is affected by efficiency and will, depending on the elasticity, influence the demand (traffic volume). The efficiency can increase by technical measures (e.g. more efficient vehicles) or by better utilization of vehicles (more people in the vehicle means more pkm per vehicle-km). It is possible that more volume increases efficiency for several reasons (the "(+)"). However, for each concrete transport mode, one has to account for the specific causal link between volume and fuel efficiency and how fuel efficiency affects the price the user finally has to pay.

\section{b) Resource scarcity loop}

Fuel (or any other resource needed to produce a $\mathrm{pkm}$ ) may change in price if the total demand for this resource changes, depending on how supply reacts to demand in the market. Besides fuels, we may think of road pricing, which reflects the resource "infrastructure capacity" that is used to produce transport. Increasing use of any limited resource will at some point lead to an increase in price, which is reflected in this feedback loop. Again, it depends on the mode how this causal relationship is modeled in detail.

\subsection{Time rebound effect in Model 1}

In addition to direct economic rebound, the IPTS study (Model 1) included time rebound, another type of rebound effect based on time efficiency in consumption. Especially in passenger transport, time is a scarce resource and may affect behavior more than money. Model 1 (like Model 2) belongs to a class of models which abstain from converting time to money (which would be a straightforward approach in economic modeling) and keep financial budgets and time budgets of users separate. The time rebound effect was considered crucial in the IPTS study, because a core characteristic of ICT is the potential to accelerate processes.

Time rebound effects in Model 1 are modeled via the following mechanisms, as shown in Fig. 1:

- Travel time budget mechanism

- Mode shift loop

These mechanisms work with time (not money as it is the case for cost efficiency loop and resource scarcity loop); a central variable is the speed of transport of each mode.

\section{a) Travel time budget mechanism}

For the transport submodel the time rebound was considered via the so-called constant travel time hypothesis, assuming that the average daily time spent in transport over the whole population is more or less stable [38] (a critique of this 
hypothesis will be addressed later in this paper). At any point in time, the given travel volumes of all modes and their current speed levels make it possible to compare actual travel time with this time budget. If there is a deficit, this will cause a shift of the modal split from slower to faster modes. If Mode $\mathrm{A}$ is currently slower than Mode B, then traffic volume will shift to mode B, with some time constants similar to the ones mentioned for economic elasticity, and also with some limitations of the substitution potential. In the full IPTS model with five modes, this can for example mean that people having to commute over a higher distance will then maybe use a private car instead of the public bus, or that car drivers faced with increasing congestion will switch to the train or metro.

\section{b) Mode shift loop}

As shown in Fig. 1, the mode-shift loop includes a causal link between the volume of each mode and the speed of this mode. This reflects the fact that utilization of each mode has an effect on time. It is important to see that this relationship can be different for each mode. For example, in public transport higher volume can lead to a better service (increased density in time and space) such as a higher frequency and more bus lines, which increases door-to-door speed for the passenger. Whereas in the private car mode, increased volume usually means that speed goes down, especially when congestion occurs. Model 1 makes this difference between "self-accelerating" and "self-limiting" transport modes and can therefore account for complex changes in demand, in particular when also the virtual modes and other effects of ICT come into play.

One of these effects is called the "time utilization effect" in the IPTS study (not represented in Fig 2b, but shown in Fig 2a): Because of mobile work that is possible to some limited, but increasing degree due to ICT, the time spent in traffic is not fully counted as transport time, i.e., a part of it is not charged from the travel time budget. Of course, the degree of time utilization is different from mode to mode (higher in public modes than in the private car mode) and changes over time with progress in mobile ICT devices and infrastructures. This is a core feature of the IPTS study. Time utilization effects can create more transport demand and influence the modal split towards public transport.

Two features of Model 1 could not be shown in Fig. 1. First, different modes of transport can share infrastructure, which means that their speeds are coupled to a certain degree (e.g. public buses may be slowed down by congestion caused by private car traffic). This can be expressed in Model 1 by so-called coupling factors for each pair of transport modes. Second, there is an overall reinforcing feedback loop of passenger transport demand which works via settlement dispersion: more traffic volume slowly increases the level of dispersion. It is the level of dispersion which decides how a time deficit is corrected; the correction is in fact a mix between the two possibilities of shifting to a faster mode or reducing the distance covered.

\footnotetext{
Accepted Author Manuscript of the following publication:

Ahmadi Achachlouei, M., Hilty, L.M. (2016): Using Systems Thinking and System Dynamics Modeling to Understand Rebound Effects. In: Marx Gomez, J., Sonnenschein, M., Vogel, U., Winter, A., Rapp, B., Giesen, N. (eds): Advances and New Trends in Environmental and Energy Informatics, Springer International Publishing Switzerland, pp. 237-255
} 


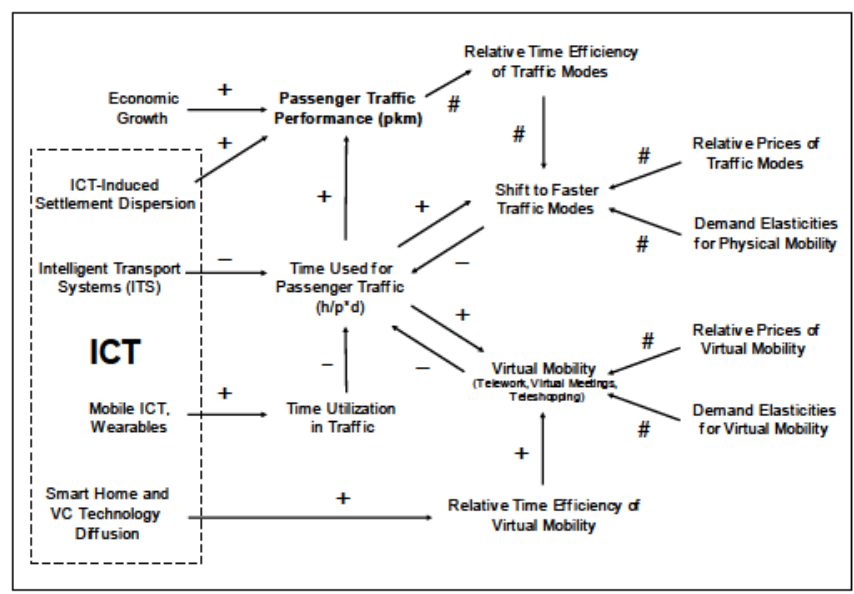

(a)

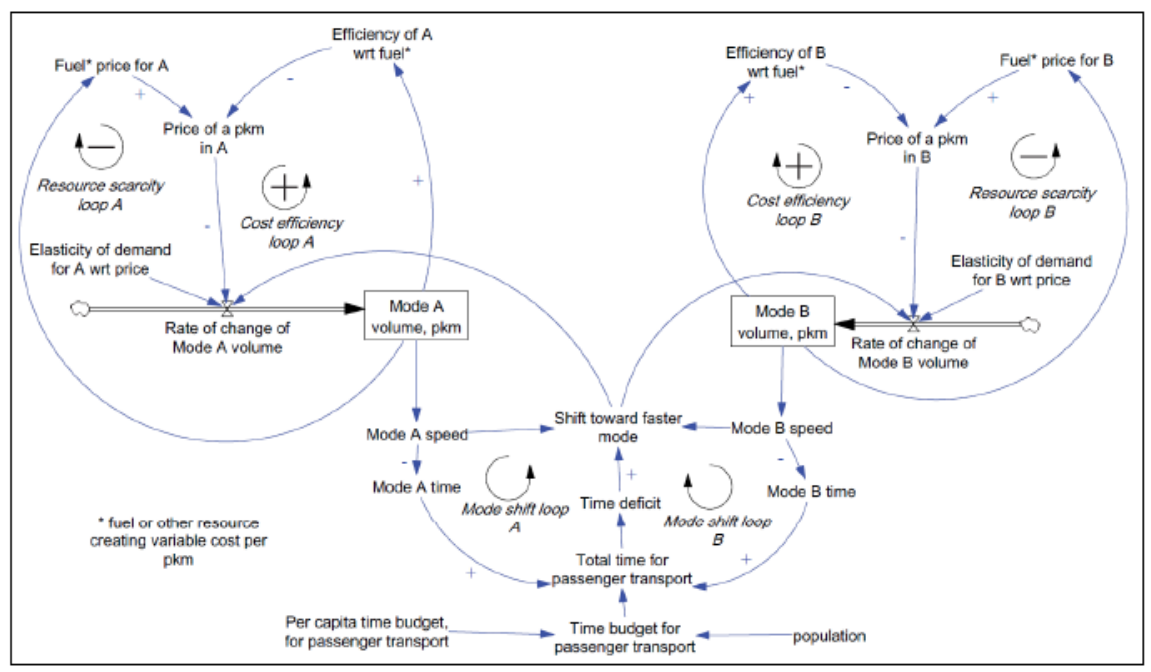

(b)

Fig. 1: Causal loop diagram for Model 1: (a) more abstract diagram for the development of passenger transport performance, taken from the IPTS interim report [31]: "ICT has second-order effects when applied passenger traffic (all applications subsumed under Intelligent Transport Systems) and thirdorder effects in the long term via settlement dispersion, time use in traffic, smart home and videoconferencing technology. The '\#' sign is used where the multidimensional variables are involved, leading to complex causal relationships." (b) less abstract diagram focused on main feedback loops 


\section{Model 2: Tourism Transport, Efficiency, and GHG Emissions}

The second model (Model 2) is taken from a study by Peeters [14] on modeling tourism transport demand considering rebound effects of technological efficiency improvement. In a similar way to Model 1, Model 2 has also addressed two types of rebound effects with regard to tourism transport [14]: direct economic rebound effects and time rebound effects (based on travel time budget).

The following subsections present how these two categories of rebound effects were addressed in Model 2.

\subsection{Direct economic rebound effect in Model 2}

As shown in Fig. 2a, the direct economic rebound effects are represented via two reinforcing feedback loops in Model 2: Efficiency enhancing loop and emissions loop.

\section{a) Efficiency enhancing loop}

This is the main reinforcing loop, which starts with investment in efficiency enhancing technology. The efficiency reduces energy consumption per seatkilometer (skm), and thus it reduces cost per skm, which in turn can induce increases in transport volume $(\mathrm{pkm})$ depending on the price elasticity of transport demand (although the economic elasticity is not clearly presented in [14]). More transport generates funds that can be used as more investment in technology improvement, creating a reinforcing loop that improves efficiency.

b) Emissions loop

The reinforcing loop of efficiency improvement transport volume does not necessarily reduce total emissions due to the increase in transport volume in the reinforcing loop. Which of the two loops of efficiency and emissions has the most impact depends on the specifics of the transport system described by the model [14].

c) Attitude loop

A third relevant loop in this system is the attitude loop, a balancing loop because an increase in environmental pressure will tend to increase the willingness to invest in pollution-saving technology, which also improves efficiency [14].

\subsection{Time rebound effects in Model 2}

Model 2, as shown in Fig. 2b, contains three reinforcing feedback loops-travel time loop, cost loop, and mode shift loop-and one balancing loop, i.e., max speed loop. The causal loop diagram in Fig. $2 b$ is based on three basic assumptions drawn from literature [14]:

\footnotetext{
Accepted Author Manuscript of the following publication:

Ahmadi Achachlouei, M., Hilty, L.M. (2016): Using Systems Thinking and System Dynamics Modeling to Understand Rebound Effects. In: Marx Gomez, J., Sonnenschein, M., Vogel, U., Winter, A., Rapp, B., Giesen, N. (eds): Advances and New Trends in Environmental and Energy Informatics, Springer International Publishing Switzerland, pp. 237-255
} 
- Tendency to travel longer distances (a significant part of a population has the aspiration to increase their range),

- Travel time budget (on a population level the total amount of time spent for actually traveling from home to destinations and back is more or less constant)

- Constant share of income (the average amount of money spent on transport per year on a population level is a constant share of income).

\section{a) Travel time loop}

Assuming a constant travel time budget, if people have more money they will be able to travel more kilometers within the constant time budget (This is valid for the whole population, but not for the individual as they can temporarily change the amount of time and money spent on travel.) From "average distance" a reinforcing loop boosts the distances traveled [14].

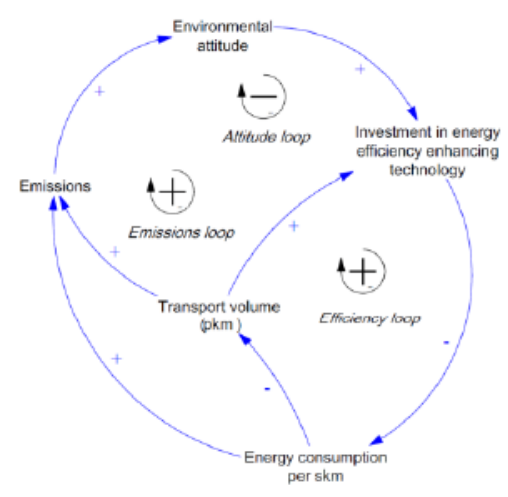

(a)

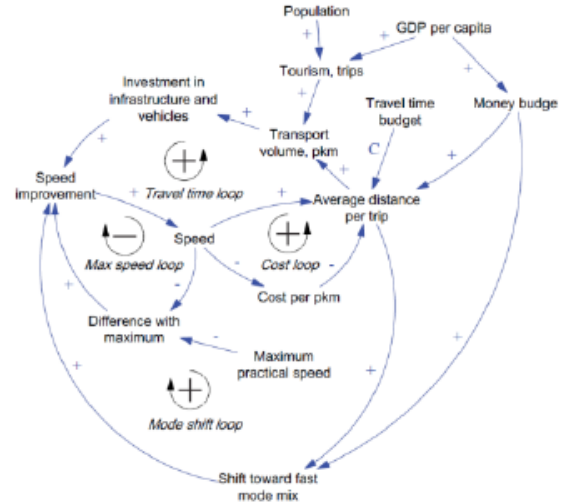

(b)

Fig. 2: Causal loop diagram for Model 2 [14]: (a) Pollution-saving loops (b) Basic forces in transport systems

\section{b) Mode shift loop}

As shown in Fig. 2b, an increase in money budget and in average travel distance will increase the share of faster modes. Faster transport modes are used over longer distances [14].

\section{c) Cost loop}

This reinforcing loop runs through cost of transport. With an increase in speed, operational costs generally reduce because productivity is increased faster than per hour operational costs, allowing for a higher number of kilometers to be sold [14]. 


\section{Main Findings and Discussion}

\subsection{Main findings from reviewing Model 1 and Model 2}

Both Model 1 and Model 2 have employed feedback loops to explore the dynamics of transport volume (in $\mathrm{pkm}$ ). A better understanding and estimation of the demand for transport volume is important because energy demand and GHG emissions are associated with transport volume.

Both models represent the same types of rebound effects in passenger transport, using feedback loops including cost efficiency and resource scarcity loops (for direct economic rebound), and a mode shift loop with travel time budget (for time rebound).

Both models showed that efficiency cannot necessarily reduce total emissions if the transport volume increases because of time rebound and direct economic rebound. These conclusions derived from the models are rooted in empirical evidence as follows. Model 1 is an implemented simulation model the results of which have been evaluated using empirical data (see [35]). Model 2 is a purely conceptual qualitative model without simulation. The validity of model 2 is justified in the original publication by reference to historical studies on the US and EU showing the existence of the feedback loops [14].

The two models included similar external variables such as population and the economic growth as drivers of transport demand. (See the upper right part in Fig. 2b and upper left part in Fig 2a). The efficiency loop modeled in Model 2 (Fig. 2a) includes investment in efficiency enhancing technology. However, investments are not explicitly represented in Model 1.

The concept of economic elasticity of demand with regard to price is used in both models. However, Model 1 addressed this in a more explicit way by presenting elasticity parameters for different transport modes.

Both models use the constant travel time budget assumption in a similar way to show the dynamics of speed versus demand; higher speed implies using the unutilized travel time to cover more distance.

\subsection{Time rebound}

The two models highlight an important aspect of rebound effects which is related to more efficient use of time. Sorrell and Dimitropoulos [4] note that time efficiency, a parallel to direct rebound from energy efficiency, has not been included in many studies that seek to quantify direct rebound effects of efficiency improvements. Time rebound occurs in two ways: first, through the rebound effects with respect to time, e.g. choosing to travel longer; second, through "trading off energy efficiency for time efficiency" [6], e.g. choosing to travel by air rather than by train.

\footnotetext{
Accepted Author Manuscript of the following publication:

Ahmadi Achachlouei, M., Hilty, L.M. (2016): Using Systems Thinking and System Dynamics Modeling to Understand Rebound Effects. In: Marx Gomez, J., Sonnenschein, M., Vogel, U., Winter, A., Rapp, B., Giesen, N. (eds): Advances and New Trends in Environmental and Energy Informatics, Springer International Publishing Switzerland, pp. 237-255
} 


\subsection{Critique of the travel time budget approach}

Both models assume that at a population level the total amount of time spent for actually traveling from home to destinations and back is more or less constant. The idea of such a travel time budget-which has been developed since $70 \mathrm{~s}$ in the field of transport research and supported by empirical studies (e.g. see [39]) — has encountered critiques. Höjer and Mattsson [40] briefly review this mechanism, its advantages and weaknesses and find it "hardly reasonable to presuppose that travel time is constant when planning for future transport systems and urban structures." They critically review some explanations of this hypothesis discussed in the literature regarding biological reasons (e.g. that "people like a certain amount of stability in both habit and behavior" may be related to evolutionary processes and cave-period humans tending to spend the same average time for daily travels) as well as economic and social explanations (see [40] for details).

It is worth further investigating the advantages and weaknesses of employing the hypothesis of constant travel time compared to other alternatives. Two points regarding the critique can be considered.

First, the travel time budget approach provides a mechanism to model the scarcity of the resource time. Without accounting for time scarcity, a model could possibly predict that someone who can afford it would travel for 24 hours per day.

Second, Model 1 already showed a way to relax the constant travel time hypothesis without loosing its advantages: the concept of (travel) time utilization, or dual use of time, mitigates some of the problems of this approach. As shown in Fig. 1a, the IPTS included the variable of time utilization in traffic (This variable is not presented in Fig. $1 \mathrm{~b}$ to make the diagram as simple as possible for the purpose of this paper), which means that if passengers can do something else while traveling (e.g., using mobile ICT), this "something else" makes travel less "time consuming". The IPTS study included several factors regarding time utilization. For example, an hour on the train while reading is not a full travel time hour. As shown in Fig. 1a, time utilization can create more transport demand and it can influence the modal split via the mechanisms already explained. It has roughly the same effect as an increase in speed.

An alternative approach (not employed in Model 1 or 2 ) is to convert time into money, leading to the question of the subjective economic value of time spent on travel. The economic value of travel time has been investigated in empirical studies since the 1970s. As an example, if drivers have the choice to pay a fee to cross a bridge or to accept detour for crossing a bridge without paying a fee, these choices can be related to their income (monetary value of their time). It is known from such studies that the value people assign to the time spent while driving a car is between $1 / 3$ and $1 / 2$ of their net hourly income [37]. So it is not the same as working, but it is related to income. The advantage of this approach is that time cost could be added to fuel cost and other variable costs, yielding one price for a $\mathrm{pkm}$. It would then be easier to apply demand elasticity data to determine the size 
of the rebound effect. However, one problem with monetizing time is that the marginal value may increase dramatically; e.g. the second hour per day spent in traffic might be much more expensive than the first one. Considering this makes the approach less different from the constant travel time budget approach than it may look like.

\subsection{Quantification of rebound effects}

Economic studies have presented the calculation of the magnitude of rebound effects. For example, Borenstein [19], in his microeconomic framework or evaluating energy efficiency rebound, provided illustrative calculations for improved auto fuel economy and lighting efficiency and showed that rebound likely reduced the net savings from these energy efficiency improvements by roughly $10 \%$ to $40 \%$.

How could such a quantitative analysis be conducted using the models discussed in this paper? Each of the models would have to be run in two versions (so-called competitive models, [41]), an original version and a version with those feedback loops cut which are responsible for rebound effects. The model outputs, such as total energy consumption of passenger transport or total passenger transport volume, could then be compared quantitatively among the two versions. Such a simulation experiment could also be refined to a larger number of model versions by disabling only one type of rebound effect at a time.

\subsection{System archetypes for rebound effects}

As we saw in Models 1 and 2, there are particular patterns of feedback for direct economic rebound and time rebound that occur in situations of efficiency improvement and generate particular patterns of behavior. Such generic structures are termed as "system archetypes" [42] which often explain certain situations, in which competing feedback loops determine the behavior of the systems and assist [25]. Future work on system archetypes for rebound effects would facilitate and standardize the future uses of systems thinking and modeling instruments in environmental policy. In such efforts, it is also useful to clarify the connections between rigorous definitions of direct rebound effects (e.g., see equations (1) to (4)) and the patterns of feedback modeled in the system archetypes.

\subsection{Contribution of systems thinking and modeling to rebound analysis}

Many economic, sociological and psychological studies have addressed different aspects, both qualitative and quantitative, of rebound effects [5]-[8]. See [18] for an overview of sociological, ecological economics, and environmental systems analysis perspectives on rebound analysis. What is the contribution of systems thinking and System Dynamics modeling to the analysis of rebound effects? Can

\footnotetext{
Accepted Author Manuscript of the following publication:

Ahmadi Achachlouei, M., Hilty, L.M. (2016): Using Systems Thinking and System Dynamics Modeling to Understand Rebound Effects. In: Marx Gomez, J., Sonnenschein, M., Vogel, U., Winter, A., Rapp, B., Giesen, N. (eds): Advances and New Trends in Environmental and Energy Informatics, Springer International Publishing Switzerland, pp. 237-255
} 
we generalize insights from our case study on rebound effects in passenger transport to rebound effects in other sectors?

First, we should note that most of existing studies in economics and sociology seek to provide empirical evidence on rebound effects and their magnitude. For example, econometric studies use private household surveys and data on elasticity of demand for useful work or energy consumption to estimate the direct rebound effect [43]; use input output models to estimate the indirect (income) rebound effect [44]; and use Computable General Equilibrium (CGE) models to address economy-wide effects [45]. Further, sociological studies seek to explain various social factors and dynamics behind the increase in consumption-factors such as search for identity, status competition, advertising, lock-in within institutional structures like the work-and-spend cycle, and individualization [46].

What systems thinking and modeling instruments provide is a set of tools such as CLDs and simulation combined with collaborative approaches to "offer a holistic way of appreciating all dimensions of a complex problem" [24] and to better understand the causal relations (circular causality) between the factors influencing a certain effect observed in a real-world context. Given the current knowledge about a system (in which a rebound effect occurs) and knowledge about historically and socially constructed influencing factors, a systems thinking and modeling approach assists in structuring a policy issue regarding rebound effects, conceptualizing and linking socio-economic causal relations, and communicating and enhancing such understanding of the system and its behavior over time in collaboration with stakeholders. Thereby, systems modeling provides a platform for testing various policy options and system intervention scenarios to mitigate rebound effects-For example, see the policy discussions in studies employing a systems approach and also addressing rebound effects: Hilty et al. [12], Stepp et al. [13], Peeters [14], and Dace et al. [15].

\section{Conclusions}

The two models we discussed represent the same types of rebound effects in passenger transport. Both are multi-modal transport models, considering the dynamic change of modal split as well. Feedback loops (closed causal chains) are an obvious concept to model rebound effects at a macro-economic level as it is done in System Dynamics (as opposed to use behavior rules at the microeconomic level in agent-based simulation).

Despite the similarities, the comparison of the two models showed that there can be much variety in the details of modeling rebound effects in passenger transport. Model 1 puts greater emphasis on the different characteristics of transport modes and how they interact, on time utilization and virtual modes, whereas Model 2 explicitly considers investment in technology and environmental attitude as variables in the main feedback loops. 
The contribution of the systems thinking and modeling approach to rebound analysis originates from its holistic approach, its capability to be built upon our empirical knowledge on rebound effects; its capability to represent various policy options and intervention scenarios; and its support for integration of rigorous simulation tools with high-level diagramming tools easy to be used by a variety of stakeholders in a collaborative modeling environment.

Future work may employ systems thinking and modeling in designing policy instruments, addressing both efficiency and rebound effects in a holistic perspective.

\section{Acknowledgements}

The authors would like to thank Empa (Technology and Society Lab), KTH (Centre for Sustainable Communications), and Vinnova, which made this work possible as a part of the first author's $\mathrm{PhD}$ project.

\section{References}

[1] O. Edenhofer, R. Pichs-Madruga, Y. Sokona, S. Agrawala, I. A. Bashmakov, G. Blanco, J. Broome, and others, Climate Change 2014: Mitigation of Climate Change: Working Group III Contribution to the Fifth Assessment Report of the Intergovernmental Panel on Climate Change. Cambridge University Press, 2014.

[2] P. H. G. Berkhout, J. C. Muskens, and J. W. Velthuijsen, "Defining the rebound effect," Energy Policy, vol. 28, no. 6-7, pp. 425-432, Jun. 2000.

[3] A. Arvesen, R. M. Bright, and E. G. Hertwich, "Considering only first-order effects? How simplifications lead to unrealistic technology optimism in climate change mitigation," Energy Policy, vol. 39, no. 11, pp. 7448-7454, Nov. 2011.

[4] S. Sorrell and J. Dimitropoulos, "The rebound effect: Microeconomic definitions, limitations and extensions," Ecol. Econ., vol. 65, no. 3, pp. 636-649, Apr. 2008.

[5] L. A. Greening, D. L. Greene, and C. Difiglio, "Energy efficiency and consumption - the rebound effect - a survey," Energy Policy, vol. 28, no. 6-7, pp. 389-401, Jun. 2000.

[6] S. Sorrell, J. Dimitropoulos, and M. Sommerville, "Empirical estimates of the direct rebound effect: A review," Energy Policy, vol. 37, no. 4, pp. 1356-1371, Apr. 2009.

[7] I. Røpke and T. H. Christensen, "Energy impacts of ICT - Insights from an everyday life perspective," Telemat. Inform., vol. 29, no. 4, pp. 348-361, Nov. 2012.

[8] W. Abrahamse, L. Steg, C. Vlek, and T. Rothengatter, "A review of intervention studies aimed at household energy conservation," J. Environ. Psychol., vol. 25, no. 3, pp. 273-291, Sep. 2005.

\footnotetext{
Accepted Author Manuscript of the following publication:

Ahmadi Achachlouei, M., Hilty, L.M. (2016): Using Systems Thinking and System Dynamics Modeling to Understand Rebound Effects. In: Marx Gomez, J., Sonnenschein, M., Vogel, U., Winter, A., Rapp, B., Giesen, N. (eds): Advances and New Trends in Environmental and Energy Informatics, Springer International Publishing Switzerland, pp. 237-255
} 
[9] J. W. Forrester, Industrial Dynamics. Cambridge Massachusetts: The MIT Press, 1961.

[10] J. D. Sterman, Business dynamics: systems thinking and modeling for a complex world, vol. 19. Irwin/McGraw-Hill Boston, 2000.

[11] G. P. Richardson, "System dynamics, the basic elements of," in Complex Systems in Finance and Econometrics, Springer, 2011, pp. 856-862.

[12] L. M. Hilty, P. Arnfalk, L. Erdmann, J. Goodman, M. Lehmann, and P. A. Wäger, "The relevance of information and communication technologies for environmental sustainability - A prospective simulation study," Environ. Model. Softw., vol. 21, no. 11, pp. 1618-1629, Nov. 2006.

[13] M. D. Stepp, J. J. Winebrake, J. S. Hawker, and S. J. Skerlos, "Greenhouse gas mitigation policies and the transportation sector: The role of feedback effects on policy effectiveness," Energy Policy, vol. 37, no. 7, pp. 2774-2787, Jul. 2009.

[14] P. Peeters, "Chapter 4 Tourism transport, technology, and carbon dioxide emissions," in Tourism and the Implications of Climate Change: Issues and Actions, vol. 3, 0 vols., Emerald Group Publishing Limited, 2010, pp. 67-90.

[15] E. Dace, G. Bazbauers, A. Berzina, and P. I. Davidsen, "System dynamics model for analyzing effects of eco-design policy on packaging waste management system," Resour. Conserv. Recycl., vol. 87, pp. 175-190, Jun. 2014.

[16] S. Sorrell, “Jevons' Paradox revisited: The evidence for backfire from improved energy efficiency," Energy Policy, vol. 37, no. 4, pp. 1456-1469, Apr. 2009 .

[17] C. Gossart, "Rebound Effects and ICT: A Review of the Literature," in ICT Innovations for Sustainability, L. M. Hilty and B. Aebischer, Eds. Springer International Publishing, 2015, pp. 435-448.

[18] M. Börjesson Rivera, C. Håkansson, A. Svenfelt, and G. Finnveden, "Including second order effects in environmental assessments of ICT," Environ. Model. Softw., vol. 56, pp. 105-115, Jun. 2014.

[19] S. Borenstein, "A microeconomic framework for evaluating energy efficiency rebound and some implications," National Bureau of Economic Research, 2013.

[20] L. Erdmann and L. M. Hilty, "Scenario Analysis: Exploring the Macroeconomic Impacts of Information and Communication Technologies on Greenhouse Gas Emissions," J. Ind. Ecol., vol. 14, no. 5, pp. 826-843, 2010.

[21] J. D. Khazzoom, "Economic Implications of Mandated Efficiency in Standards for Household Appliances," Energy J., vol. 1, no. 4, pp. 21-40, Oct. 1980 . 
[22] T. H. Oum, W. G. Waters, and J.-S. Yong, "Concepts of price elasticities of transport demand and recent empirical estimates: an interpretative survey," $J$. Transp. Econ. Policy, pp. 139-154, 1992.

[23] P. Hjorth and A. Bagheri, "Navigating towards sustainable development: A system dynamics approach," Futures, vol. 38, no. 1, pp. 74-92, Feb. 2006.

[24] N. C. Nguyen, D. Graham, H. Ross, K. Maani, and O. Bosch, "Educating systems thinking for sustainability: experience with a developing country," Syst. Res. Behav. Sci., vol. 29, no. 1, pp. 14-29, 2012.

[25] J. Mingers and L. White, "A review of the recent contribution of systems thinking to operational research and management science," Eur. J. Oper. Res., vol. 207, no. 3, pp. 1147-1161, Dec. 2010.

[26] E. F. Wolstenholme, "Qualitative vs quantitative modelling: the evolving balance," J. Oper. Res. Soc., pp. 422-428, 1999.

[27] N. Videira, F. Schneider, F. Sekulova, and G. Kallis, "Improving understanding on degrowth pathways: An exploratory study using collaborative causal models," Futures, vol. 55, pp. 58-77, 2014.

[28] L. Erdmann and F. Wurtenberger, "The future impact ICT on environmental sustainability. First Interim Report. Identification and global description of economic sectors," Institute for Prospective Technology Studies (IPTS), Sevilla, 2003.

[29] L. Erdmann and S. Behrendt, "The future impact ICT on environmental sustainability. Second Interim Report," Institute for Prospective Technology Studies (IPTS), Sevilla, 2003.

[30] J. Goodman and V. Alakeson, "The future impact ICT on environmental sustainability. Third Interim Report. Scenarios," Institute for Prospective Technology Studies (IPTS), Sevilla, 2003.

[31] L. M. Hilty, P. Wäger, M. Lehmann, R. Hischier, T. F. Ruddy, and M. Binswanger, "The future impact of ICT on environmental sustainability. Fourth Interim Report. Refinement and quantification," Institute for Prospective Technological Studies (IPTS), Sevilla, 2004.

[32] P. Arnfalk, "The future impact ICT on environmental sustainability. Fifth Interim Report. Evaluation and Recommendations," Institute for Prospective Technology Studies (IPTS), Sevilla, 2004.

[33] L. Erdmann, L. M. Hilty, J. Goodman, and P. Arnfalk, "The future impact ICT on environmental sustainability. Synthesis Report," Institute for Prospective Technology Studies (IPTS), Sevilla, 2004.

[34] P. Wäger, L. M. Hilty, P. Arnfalk, L. Erdmann, and J. Goodman, "Experience with a System Dynamics model in a prospective study on the future

Accepted Author Manuscript of the following publication:

Ahmadi Achachlouei, M., Hilty, L.M. (2016): Using Systems Thinking and System Dynamics Modeling to Understand Rebound Effects. In: Marx Gomez, J., Sonnenschein, M., Vogel, U., Winter, A., Rapp, B., Giesen, N. (eds): Advances and New Trends in Environmental and Energy Informatics, Springer International Publishing Switzerland, pp. 237-255 
impact of ICT on environmental sustainability," in IEMSs 3rd Biennial Meeting Summit on Environmental Modeling and Software, Burlington, USA, 2006.

[35] M. A. Achachlouei and L. M. Hilty, "Modeling the Effects of ICT on Environmental Sustainability: Revisiting a System Dynamics Model Developed for the European Commission," in ICT Innovations for Sustainability, L. M. Hilty and B. Aebischer, Eds. Springer International Publishing, 2015, pp. 449-474.

[36] L. M. Hilty, Ökologische Bewertung von Verkehrs-und Logistiksystemen: Ökobilanzen und Computersimulation. IWÖ, 1994.

[37] L. M. Hilty, "Umweltbezogene Informationsverarbeitung-Beiträge der Informatik zu einer nachhaltigen Entwicklung," Habil Hambg., 1997.

[38] G. Hupkes, "The law of constant travel time and trip-rates," Futures, vol. 14, no. 1, pp. 38-46, Feb. 1982.

[39] D. Metz, "The Myth of Travel Time Saving," Transp. Rev., vol. 28, no. 3, pp. 321-336, May 2008.

[40] M. Höjer and L.-G. Mattsson, "Determinism and backcasting in future studies," Futures, vol. 32, no. 7, pp. 613-634, Sep. 2000.

[41] L. M. Hilty, R. Meyer, and T. F. Ruddy, "A general modelling and simulation system for sustainability impact assessment in the field of traffic and logistics," Environ. Inf. Syst. Ind. Public Adm. Idea Group Publ., pp. 167-185, 2001.

[42] E. Wolstenholme, "Using generic system archetypes to support thinking and modelling," Syst. Dyn. Rev., vol. 20, no. 4, pp. 341-356, 2004.

[43] J. Schleich, B. Mills, and E. Dütschke, "A brighter future? Quantifying the rebound effect in energy efficient lighting," Energy Policy, vol. 72, pp. 35-42, Sep. 2014.

[44] R. Kok, R. M. J. Benders, and H. C. Moll, "Measuring the environmental load of household consumption using some methods based on input-output energy analysis: A comparison of methods and a discussion of results," Energy Policy, vol. 34 , no. 17 , pp. 2744-2761, Nov. 2006.

[45] S. Grepperud and I. Rasmussen, "A general equilibrium assessment of rebound effects," Energy Econ., vol. 26, no. 2, pp. 261-282, Mar. 2004.

[46] I. Røpke, "Theories of practice - New inspiration for ecological economic studies on consumption," Ecol. Econ., vol. 68, no. 10, pp. 2490-2497, Aug. 2009. 